Voix et Images

voixetimages

\title{
Le retrait de l'image du poème
}

\section{Stéphane Inkel}

Volume 36, numéro 2 (107), hiver 2011

URI : https://id.erudit.org/iderudit/1002447ar

Aller au sommaire du numéro

Éditeur(s)

Université du Québec à Montréal

ISSN

0318-9201 (imprimé)

1705-933X (numérique)

Découvrir la revue

Citer ce compte rendu

Inkel, S. (2011). Compte rendu de [Le retrait de l'image du poème]. Voix et Images, 36(2), 133-136. d'utilisation que vous pouvez consulter en ligne.

https://apropos.erudit.org/fr/usagers/politique-dutilisation/ 
E S S A I S / ÉT U D ES

Le retrait de l'image du poème

$+++$

STÉPHANE INKEL

Université Queen's

Dans sa dernière chronique, consacrée à la tendance lourde de l'interdisciplinarité affectant les études littéraires, Robert Dion se demandait s'il y avait encore quelqu'un pour se désoler de la difficulté grandissante de publier des monographies sur des auteurs uniques «sans [les] renvoyer à tout [leur] "environnement" culturel ${ }^{1}$ ». C'est à une semblable préoccupation que Frédérique Bernier, enseignante au cégep de SaintLaurent et membre du comité de rédaction des cahiers Contre-jour, semble faire écho dans les premières lignes de son essai La voix et l'os. Imaginaire de l'ascèse chez SaintDenys Garneau et Samuel Beckett ${ }^{2}$, lorsqu'elle affirme que le rapprochement de ces deux œuvres «peut sembler un geste à première vue étonnant, voire frivole» (9). Étonnant, peut-être, si l'on s'en tient précisément à la différence du contexte culturel dans lequel chacun a élaboré son œuvre, mais frivole? Force est de constater que cet ouvrage, portant sur le rapport existant entre une poétique de l'ascèse que SaintDenys Garneau partage avec l'écrivain irlandais, fait au contraire la preuve de sa grande pertinence, tout comme de celle de la perspective comparatiste qui est la sienne. Pour saisir un premier aspect de cette pertinence, il faut commencer par rappeler qu'une partie non négligeable de la critique garnélienne a fait du christianisme (qu'il soit perçu de manière positive ou négative) et de la modernité des «paradigmes mutuellement exclusifs » (17) que l'auteure cherche précisément à réconcilier à partir du prisme esthétique de l'idéal ascétique propre à l'art moderne, notamment mis en lumière par Charles A. Riley ${ }^{3}$. Interroger ce qu'il y a d'intrinsèquement moderne dans l'ascèse chrétienne et ses représentations du corps constitue l'un des intérêts de cette relecture qui mesure avec justesse la réussite aujourd'hui indéniable de Garneau, mais aussi ses limites, cette sorte de "piétinement» (239) qui l'aura laissé sur le seuil d'une révolution littéraire réalisée par Beckett.

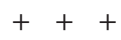

1 Robert Dion, «Interdisciplinarités», Voix et Images, vol. XXXV, n 3, printemps-été 2010, p. 139. 2 Frédérique Bernier, La voix et l'os. Imaginaire de l'ascèse chez Saint-Denys Garneau et Samuel Beckett, Montréal, Presses de l'Université de Montréal, coll. «Espace littéraire», 2010, 256 p. 3 Voir notamment Charles A. Riley, The Saints of Modern Art. The Ascetic Ideal in Contemporary Painting, Sculpture, Architecture, Music, Dance, Literature and Philosophy, Hanover/Londres, University Press of New England, 1998, 353 p. 
Certains se souviendront d'une remarque allusive mais éclairante de Jacques Brault, en préface d'une réédition des poèmes de Garneau: «Pendant trois ou quatre années, en pleine jeunesse, Saint-Denys Garneau va vieillir, littéralement, à l'instar des personnages beckettiens, pour finir, sculpture imprévue de Giacometti, en colonne vertébrale ébranchée, "Debout en os et les yeux fixés sur le néant" ${ }^{4}$.» On se rend compte immédiatement à la lecture de La voix et l'os de la justesse de l'intuition, que l'on pense aux nombreuses figures de dédoublement et de recommencement, à leur «réflexivité autodestructrice» (10) ou aux effets ponctuels de cassure syntaxique et rythmique de leurs œuvres, sans parler du minutieux travail de démembrement des corps toujours plus insistant chez ces deux contemporains, un dépouillement qui va jusqu'à l'os, de la colonne vertébrale «ébranchée», chez Saint-Denys Garneau, à la réduction au crâne dans les derniers textes de Beckett. Mais par-delà ces thèmes ou procédés d'écriture communs, c'est l'entreprise de dénuement qui affecte la voix et l'image que cherche à cerner Frédérique Bernier, réduction qui s'effectue de part et d'autre par l'entremise d'une «appropriation esthétique d'un héritage chrétien » (24), en particulier du geste paradoxal de la "kénose» paulinienne, ce dépouillement de soi-même que l'auteure repère jusque dans le détournement des images chrétiennes elles-mêmes, et qui permet de donner à la négativité garnélienne une tout autre portée, loin de celle que l'on a pu attribuer aux débats intérieurs propres au Journal.

La décrépitude du corps, particulièrement visible dans son théâtre, est en quelque sorte l'étendard de l'œuvre de Beckett, avec ses rampants, ses paralytiques et autres troncs plantés dans une jarre comme des fleurs. Le tableau est plus modeste chez Saint-Denys Garneau. Mais si l'on ne saurait retrouver chez lui pareille pléthore de maux et de postures, le morcellement dont le corps fait l'objet n'y est toutefois pas banal, et Frédérique Bernier, attentive aux effets d'incarnation et de défiguration qui tour à tour occupent la représentation, nous rappelle avec à-propos comment ce morcellement représente l'envers d'un désir d'unité qui n'aura de cesse de l'accompagner. Fêlure de la voix ou découpe de la chair, le dépouillement, parfois jusqu'à l'os, dont le corps fait l'objet est ainsi, dans la première partie de l'essai, analysé en fonction de la quête d'authenticité de la voix, notamment à travers le commentaire du célèbre extrait du Journal «Le mauvais pauvre» et de son image finale d'« épine dorsale [...] ébranchée». Modestie inhérente à la condition canadienne-française ou mauvaise conscience face à «l'hubris » de la création ? La deuxième partie, consacrée au dédoublement qui ne manque pas de découler de la tentative proprement moderne d'autoengendrement et de la négation de l'Autre qu'elle implique, tranche en faveur de la seconde, ce qui permet de situer le projet garnélien dans une esthétique de la modernité allant bien au-delà de la question du style et trouvant son origine dans le fonctionnement même de la mimésis. À la lumière de la multiplication des voix et des corps d'emprunt qui surgissent de la non-coïncidence à soi du sujet de L'innommable, l'essai interroge ainsi le moment de bascule du recueil Regards et jeux dans l'espace où le sujet en quête d'unité, un temps incarné par la figure de l'enfant, cède le pas à

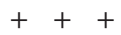

4 Jacques Brault, «Préface», Saint-Denys Garneau, Poèmes choisis, Saint-Hippolyte, Éditions du Noroît, 1993, p. 9, citê dans Frédérique Bernier, La voix et l'os, p. 19. 
des figures de double plus inquiétantes, comme c'est le cas dans les poèmes «Accompagnement» ou «Cage d'oiseau ». On le sait, le jeu, par lequel l'enfant pouvait disposer du monde dans les premiers poèmes du recueil, sera par la suite jugé sévèrement par Saint-Denys Garneau, «symbole de l'hubris littéraire [et] de la prétention du poète à se saisir de l'absolu» (132). Ce retournement contre soi du regard qui se fait accusateur permet donc de passer d'un double à un autre, au «mauvais», «miroir d'une conscience créatrice coupable» (145). Beckett a d'ailleurs vécu comme une «révélation» la décision, racontée de manière elliptique dans La dernière bande, de travailler à l'appauvrissement de la vision. Le retranchement du sujet et le travail de réduction de ses propres moyens poétiques sont pour ainsi dire demeurés insus chez Saint-Denys Garneau, traduits en une exigence d'authenticité ne cessant de buter contre «la logique de la mimésis, qui est celle-là même du double, et en vertu de laquelle le propre n'apparaît jamais qu'à la faveur de l'impropre» (146). Posé en termes esthétiques, le paradoxe de cette œuvre, longuement soupesée par des héritiers qui hésitaient avant de s'y reconnaître, atteint un degré de clarté non négligeable, entre le piège de la sincérité, qui confine au mutisme, et l'autodestruction proprement moderne du "principe même dont elle procède» (145), qui remanie profondément le rapport au visible, comme c'est le cas chez Beckett. Chez Garneau, toutefois, ce remaniement demeure à l'état de promesse.

Qu'est-ce qui aura manqué à l'écrivain pour qu'il fasse de cette défiguration du visible un projet à part entière? Qu'est-ce qui différencie le dépouillement poétique garnélien du retournement radical de la voix beckettienne sur ses propres conditions d'énonciation? Ces questions alimentent la dernière partie de l'ouvrage, très riche, consacrée à la question de l'image et à ce que Frédérique Bernier qualifie de "poétique de l'icône» (224). Avec ces transpositions de l'image sainte traditionnelle que l'on retrouve dans certains poèmes posthumes, particulièrement dénudés, les «confins du visible», pour le dire avec le poème «Figures à nos yeux» finement commenté par Bernier, s'offrent «à la trouée de visages qui l'aveuglent» (224). Cette trouée de l'image demeure toutefois relative, représentée plutôt que représentante (aveuglante), nostalgie du visible plutôt qu' « acquiescement à l'écart, à la déchirure» (225). Cette opération de « kénose » de l'image qui, dans le paradigme hérité du catholicisme, implique le corps qui en est le fondement, sera exemplairement conduite par le testament littéraire de Beckett, le poème «Comment dire» étant le lieu où le désir de voir, radicalement exposé par sa versification bégayante, se retourne en «renon ce[ment] au spectacle de l'image » (230). Frédérique Bernier montre bien que ce refus qui se manifeste dans un désir de voir demeurant sur le seuil fait de la «faillite» du poème son véritable séjour, celui-là même, en définitive, que Saint-Denys Garneau aura refusé d'habiter autrement que par le mutisme et la mort.

Lire le rapport au visible chez cet écrivain qui est à sa manière - différente de celle du peintre qu'il était aussi - un poète du paysage, n'est certes pas nouveau ${ }^{5}$.

5 Voir Pierre Nepveu, «Paysages du sujet», Intérieurs du Nouveau Monde, Montréal, Boréal, coll. «Papiers collés», 1998, p. 157-177, et plus récemment l'ouvrage d'Antoine Boisclair, L'école du regard. Poésie et peinture chez SaintDenys Garneau, Roland Giguère et Robert Melançon, Montréal, Fides, 2009, 432 p. 
Le faire à partir de cette poétique de l'ascèse qui s'exprime dans ses derniers poèmes permet toutefois d'interroger ce qu'il y a d'intrinsèquement moderne dans le catholicisme de Garneau, et qui fait toute la richesse de son imaginaire paradoxal. 